\title{
ANALISIS PENYELESAIAN TINDAK LANJUT HASIL PEMERIKSAAN AUDITOR INSPEKTORAT KABUPATEN SUMBAWA BARAT
}

\author{
Agus Harinurhady, Ahmad Rifa'i, \& Alamsyah \\ Universitas Mataram, Indonesia \\ Email: gerogge76@gmail.com
}

\begin{abstract}
Abstrak: Analisis Penyelesaian Tindak Lanjut Hasil Pemeriksaan Auditor Inspektorat Kabupaten Sumbawa Barat. Penelitian ini dikaji dari perspektif auditi dengan menggunakan pendekatan kualitatif, metode studi kasus dan teknik analisis tematik. Fenomena penelitian ini berdasarkan pada laporan hasil pemantauan tahunan oleh unit pemantauan Inspektorat Kabupaten Sumbawa Barat yang menunjukkan adanya fakta bahwa penyelesaian tindak lanjut masih ada yang berstatus dalam proses dan belum ditindaklanjuti. Hasil penelitian menemukan kurangnya komunikasi pada tingkatan manajemen SKPD Kabupaten Sumbawa Barat dan masih kurangnya Sumber Daya Manusia (SDM) yang kompeten, sehingga penyelesaian tindak lanjut belum tercapai secara maksimal yang dibuktikan dengan masih adanya status penyelesaian yang belum dan/atau tidak ditindaklanjuti. Untuk ke depannya agar kepala/pimpinan SKPD yang secara umum memiliki komitmen dalam upaya penyelesaian dapat mengupayakan komunikasi yang lebih baik dan melibatkan semua komponen dalam organisasi dengan membentuk pola hubungan tugas.
\end{abstract}

Kata Kunci: audit, pemeriksaan, pengawasan, pemantauan, tindak lanjut.

\begin{abstract}
Settlement Analysis of Follow-up Results of the Examination of the Auditor West Sumbawa District Inspectorates. This research examined from the perspective of an auditee using a qualitative approach, case study method, and technique of thematic analysis. The phenomenon of this research report is based on the results of monitoring yearly by the monitoring unit of the Inspectorate of Western Sumbawa district that shows the existence of the fact that the completion of follow-up there still are in the process and not to be follow up. The study results found a lack of communication on the work unit management level of West Sumbawa Regency and still lack the human resources (HR) are competent, so the completion of follow-up has not reached its full potential as evidenced by the completion status still has not been and/or not acted upon. For the future so that the head/leader of the work unit, which has a commitment to the quest of completion can seek better communication and involving all the components in the organization by forming a pattern of relationship tasks.
\end{abstract}

Keywords: auditing, examination, follow-up, monitoring, supervision.

\section{PENDAHULUAN}

Kebijakan pengawasan Pemerintah

Kabupaten Sumbawa Barat merupakan salah

satu bentuk dan tekad untuk mendukung

cita-cita reformasi untuk mewujudkan tata

kelola pemerintahan yang bersih dan berwibawa sebagai konsekuensi untuk menciptakan kabupaten yang berperadaban fitrah. Kebijakan tersebut diambil oleh manajemen (instansi atau pejabat yang mempunyai kewenangan mengambil keputusan di bidang pengawasan) dan 
dijadikan sebagai pedoman bagi seluruh anggota organisasi APIP dalam melaksanakan tugas-tugas pengawasannya (Inspektorat KSB, 2015).

Inspektorat Kabupaten Sumbawa Barat sebagai APIP (Aparat Pengawas Intern Pemerintah) memiliki peran dan fungsi melaksanakan tugas pengawasan urusan pemerintahan yang diatur dalam pasal 4 Peraturan Menteri Dalam Negeri nomor 64 tahun 2007. Inspektorat provinsi, kabupaten/kota mempunyai fungsi sebagai perencanaan program pengawasan; perumusan kebijakan dan fasilitas pengawasan; pemeriksaan, pengusutan, pengujian dan penilaian pengawasan.

Auditor adalah pelaksana pengawasan yang mempunyai tugas pokok untuk melaksanakan pengawasan intern pada instansi pemerintah dan memberikan rekomendasi berdasarkan temuan-temuan pemeriksaan yang disajikan dalam Laporan Hasil Pemeriksaan (LHP). Manfaat pengawasan internal melalui pemeriksaan auditor tidak hanya berupa banyaknya temuan yang dilaporkan, namun juga berupa efektivitas tindak lanjut oleh auditi. Pengawasan internal akan menjadi sia-sia tanpa tindakan perbaikan dalam penyelesaian tindak lanjut sehingga tujuan pengawasan tidak tercapai yakni peningkatan kinerja bagi organisasi dan akan menimbulkan ketidakpercayaan publik (Hasmawali, 2012).

Tindak Lanjut Hasil Pemeriksaan (TLHP) dalam lingkup pemerintah daerah di Indonesia telah diatur dalam Peraturan Pemerintah Republik Indonesia Nomor 79 Tahun 2005 tentang Pedoman Pembinaan dan Pengawasan Penyelenggaraan
Pemerintahan Daerah, Peraturan Menteri Dalam Negeri Nomor 23 tahun 2007 tentang Pedoman Tata Cara Pengawasan atas Penyelenggaraan Pemerintah Daerah dan Peraturan Menteri Negara Pendayagunaan Aparatur Negara Nomor 9 tahun 2009 tentang Pedoman Umum Pelaksanaan, Pemantauan, Evaluasi dan Pelaporan Tindak Lanjut Hasil Pengawasan Fungsional. Tuntutan kepatuhan terhadap penyelesaian tindak lanjut hasil pemeriksaan auditor atau APIP di Indonesia dalam peraturan tersebut di atas, secara hukum mengisyaratkan kewajiban untuk penyelesaiannya.

Penelitian ini bertujuan untuk mengetahui bagaimana penyelesaian tindak lanjut yang telah dilakukan oleh SKPD di Kabupaten Sumbawa Barat. Adanya tindak lanjut yang belum dan/atau tidak ditindaklanjuti menjadi pemicu urgensi dalam penyelesaian tindak lanjut. Ketika rekomendasi yang lama belum selesai ditindaklanjuti, maka akan muncul rekomendasi yang baru atas hasil pemeriksaan berikutnya sehingga rekomendasi auditor akan menumpuk yang tentu saja akan berpengaruh terhadap penilaian kinerja dari pejabat SKPD. Terhadap ketidakpatuhan penyelesaian tindak lanjut oleh SKPD yang tidak merespon beberapa tahapan peringatan, maka penyelesaian tindak lanjut temuan administrasi akan dilaporkan ke pimpinan APIP dan untuk temuan keuangan akan dilimpahkan ke Majelis Pertimbangan Tuntutan Ganti Rugi (MP-TGR).

Berdasarkan hal itu maka perlu adanya kesadaran yang tinggi dari SKPD untuk segera menuntaskan temuan APIP agar permasalahan tidak berlarut-larut dan 
terhindar dari sanksi sesuai dengan peraturan yang berlaku. sehingga dapat mewujudkan pemerintahan yang bersih dan berwibawa.

Konsep kepatuhan yang dijelaskan oleh Tyler, (dalam Saleh dan Susilowati, 2004) menyatakan bahwa perspektif normatif berhubungan dengan apa yang dianggap sebagai moral dan berlawanan dengan kepentingan pribadi, sehingga cenderung untuk mematuhi hukum yang dianggap sesuai dan konsisten dengan norma-norma internalnya, yang dianggap sebagai suatu keharusan (Dewi \& Pamudji, 2013).

Ripley \& Franklin, 1986 dalam (Akib, 2010) memperkenalkan 2 (dua) pendekatan dalam implementasi kebijakan yaitu, pendekatan kepatuhan yang mengupayakan untuk membangun kepatuhan agen atau individu sebagai bawahan terhadap agen atau individu sebagai atasan dalam suatu organisasi dan pendekatan faktual yang berasumsi bahwa terdapat banyak faktor yang mempengaruhi proses implementasi kebijakan yang mengharuskan pelaksana kebijakan agar lebih leluasa mengadakan penyesuaian.

Penelitian mengenai penyelesaian TLHP sudah cukup banyak dilakukan oleh penelitipeneliti sebelumnya di antaranya yang telah dilakukan Prihartono (2009) yang meneliti pelaksanaan pengawasan fungsional dalam rangka menuju optimalisasi kinerja pada Inspektorat Jenderal Departemen Pertanian, Hasanah (2012) yang meneliti tentang Studi Fenomenologis Terhadap Kualitas Audit Aparat Inspektorat Daerah (Studi pada Inspektorat Provinsi NTB), Arini (2014) yang menganalisis peran manajemen dalam tindak lanjut laporan hasil pemeriksaan oleh satuan kerja pemeriksaan intern di RSUP Sanglah Denpasar, tahun 2012, Hasymi (2016) yang meneliti tentang evaluasi tindak lanjut temuan audit internal sebagai unsur mengoptimalkan pengelolaan keuangan dan Suryanto (2016) yang meneliti tentang studi keterlambatan tindak lanjut temuan hasil pemeriksaan Inspektorat daerah Kabupaten Kulonprogo D.I Yogyakarta dan implementasi manajerial.

Mengacu pada uraian penelitianpenelitian sebelumnya dapat dijelaskan bahwa penyelesaian TLHP dikaji berdasarkan perspektif dari pelaku dalam SKPD yang dilandaskan pada Peraturan Menteri Pendayagunaan Aparatur Negara nomor 9 tahun 2009. Dalam konteks pengawasan, auditi harus mengedepankan kepatuhan untuk mengikuti prosedur, standar, dan aturan dalam upaya penyelesaian tindak lanjut sesuai dengan rekomendasi auditor untuk mendapatkan keyakinan yang wajar terhadap efektivitas dan efisiensi organisasi.

Terlaksananya penyelesaian tindak lanjut oleh auditi tersebut adalah wujud keberhasilan dalam proses implementasi kebijakan. Kriteria keberhasilan implementasi kebijakan menurut Edward III, 1984 dalam (Akib, 2010) ada 4 (empat) faktor yakni, komunikasi, sumber daya, sikap birokrasi atau pelaksana dan struktur organisasi, termasuk tata aliran kerja birokrasi.

Penyelesaian TLHP oleh SKPD Kabupaten Sumbawa Barat dilakukan pemantauan sesuai dengan amanat Peraturan Menteri Negara Pendayagunaan Aparatur Negara nomor 9 tahun 2009. Pemantauan tersebut dilaksanakan oleh unit pemantauan Inspektorat Kabupaten Sumbawa Barat yaitu 
Tabel 1: Rekapitulasi LHPT Unit Pemantau Inspektorat Kabupaten Sumbawa Barat

\begin{tabular}{|c|c|c|c|c|c|c|c|}
\hline \multirow[b]{2}{*}{ Kode } & \multirow[b]{2}{*}{ Jenis Temuan } & \multirow[b]{2}{*}{$\begin{array}{l}\text { Jumlah } \\
\text { Temuan }\end{array}$} & \multirow[b]{2}{*}{$\begin{array}{c}\text { Jumlah } \\
\text { Rekomendasi }\end{array}$} & \multicolumn{4}{|c|}{ Status TLHP } \\
\hline & & & & $\begin{array}{l}\text { Sudah } \\
\text { di TL }\end{array}$ & $\begin{array}{c}\text { Dalam } \\
\text { Proses } \\
\text { TL }\end{array}$ & $\begin{array}{l}\text { Belum } \\
\text { di TL }\end{array}$ & $\begin{array}{c}\text { Tdk } \\
\text { Dapat di } \\
\text { TL }\end{array}$ \\
\hline 01 & $\begin{array}{l}\text { Temuan terhadap } \\
\text { kerugian negara/daerah }\end{array}$ & 11 & 12 & 5 & 7 & 0 & 0 \\
\hline 02 & $\begin{array}{l}\text { Temuan terhadap } \\
\text { pajak/retribusi yang } \\
\text { belum dibayar }\end{array}$ & 23 & 22 & 12 & 10 & 0 & 0 \\
\hline 03 & $\begin{array}{l}\text { Temuan terhadap } \\
\text { masalah administrasi }\end{array}$ & 418 & 471 & 344 & 123 & 4 & 0 \\
\hline & JUMLAH & 452 & 505 & 361 & 140 & 4 & 0 \\
\hline
\end{tabular}

Sumber: LHPT Unit Pemantauan Inspektorat KSB Periode Januari 2016

sub bagian evaluasi dan pelaporan sebagai penanggungjawab administrasi penyelesaian TLHP. Laporan Hasil Pemantauan Tahunan (LHPT) disusun dengan mengelompokkan temuan dalam LHP auditor menjadi 3 (tiga) jenis temuan, yaitu: temuan terhadap kerugian negara/daerah, temuan terhadap pajak/retribusi yang belum dibayar dan temuan terhadap masalah administratif. Jenis temuan tersebut menyajikan 4 (empat) status penyelesaian tindak lanjut yang telah dilaksanakan oleh SKPD yaitu status selesai, status dalam proses, status belum ditindaklanjuti dan status tidak dapat ditindaklanjuti.

Kondisi status penyelesaian TLHP oleh SKPD dan Desa di Kabupaten Sumbawa Barat dalam rekapitulasi LHPT untuk periode Januari 2016 disajikan dalam Tabel 1. Berdasarkan dari data rekapitulasi penyelesaian tindak lanjut di atas, dapat dilihat adanya fakta penyelesaian TLHP yang masih berstatus dalam proses dan belum ditindaklanjuti. Penelitian ini mencoba untuk menyelidiki secara cermat dengan melakukan proses analisis tentang kepatuhan SKPD dalam pelaksanaan penyelesaian tindak lanjut yang dilakukan oleh subjek (orang-orang yang terlibat) terkait dengan tugas pokok dan fungsi yang diemban oleh masing-masing subjek/individu (pejabat pada SKPD) sesuai dengan rekomendasi auditor Inspektorat Kabupaten Sumbawa Barat.

\section{METODE}

Penelitian ini menggunakan pendekatan kualitatif dengan metode studi kasus (case study) dan difokuskan pada SKPD yang status penyelesaian TLHP-nya tidak dan/atau belum selesai/sah. Tipe desain penelitian yang digunakan adalah Type 3 (multiple-case design (holistic)) karena menggunakan beberapa objek kasus yang dilaksanakan oleh beberapa SKPD dengan menggunakan satu unit analisis yaitu penyelesaian TLHP.

Teknik analisis yang digunakan adalah analisis tematik terhadap data hasil wawancara yang diperoleh dari informan sebagai kepala/pimpinan SKPD, Sekretaris SKPD dan Bendahara pengeluaran SKPD di Kabupaten Sumbawa Barat. Analisis tematik menurut Braun dan Clarke dalam (Sofyani, 2015) digunakan untuk mengidentifikasi, menganalisis, dan melaporkan pola-pola tema dalam data yang berfokus pada aspek 
tertentu yang paling relevan serta memungkinkan peneliti untuk terlibat dengan teori.

\section{HASIL DAN PEMBAHASAN}

Data penelitian diperoleh dengan mengkategorikan SKPD yang memiliki status tindak lanjut dalam proses dan/atau belum ditindaklanjuti lebih dari 2 (dua) rekomendasi berdasarkan LHPT unit pemantauaan Inspektorat Kabupaten Sumbawa Barat untuk periode laporan Januari 2016. Berdasarkan pengkatagorian tersebut diperoleh data seperti pada Tabel 2 sebagai berikut:

Pelaksanaan pemeriksaan sampai dengan penyelesaian TLHP merupakan suatu rangkaian proses pengawasan sesuai dengan Peraturan Menteri Negara Pendayagunaan Aparatur Negara nomor 9 tahun 2009 yang menyatakan "Pengawasan sebagai suatu proses merupakan rangkaian tidak terputus yang dimulai dari perencanaan pengawasan sampai dengan hasil pengawasan selesai ditindaklanjuti". Inspektorat Kabupaten Sumbawa Barat juga melakukan pemantauan terhadap penyelesaian TLHP oleh SKPD guna menjamin terlaksananya penyelesaian TLHP sesuai dengan rekomendasi dari auditor.

Peneliti melakukan interpretasi hasil penelitian penyelesaian TLHP yang dilakukan oleh SKPD di Kabupaten Sumbawa Barat dengan menyandingkannya dengan teori, konsep, regulasi yang berlaku dan hasil-hasil penelitian terdahulu yang tentu saja memiliki keterkaitan dengan penelitian ini. Peneliti telah melakukan klaster ke dalam 4 (empat) tema berdasarkan pada kriteria keberhasilan dalam implementasi kebijakan tentang penyelesaian tindak lanjut terhadap rekomendasi auditor Inspektorat dalam Laporan Hasil Pemeriksaan yang dilakukan oleh SKPD pada Kabupaten Sumbawa Barat.

Tabel 2. Objek Penelitian berdasarkan kriteria lebih dari 2 (dua) rekomendasi yang berstatus dalam proses dan belum ditindaklanjuti

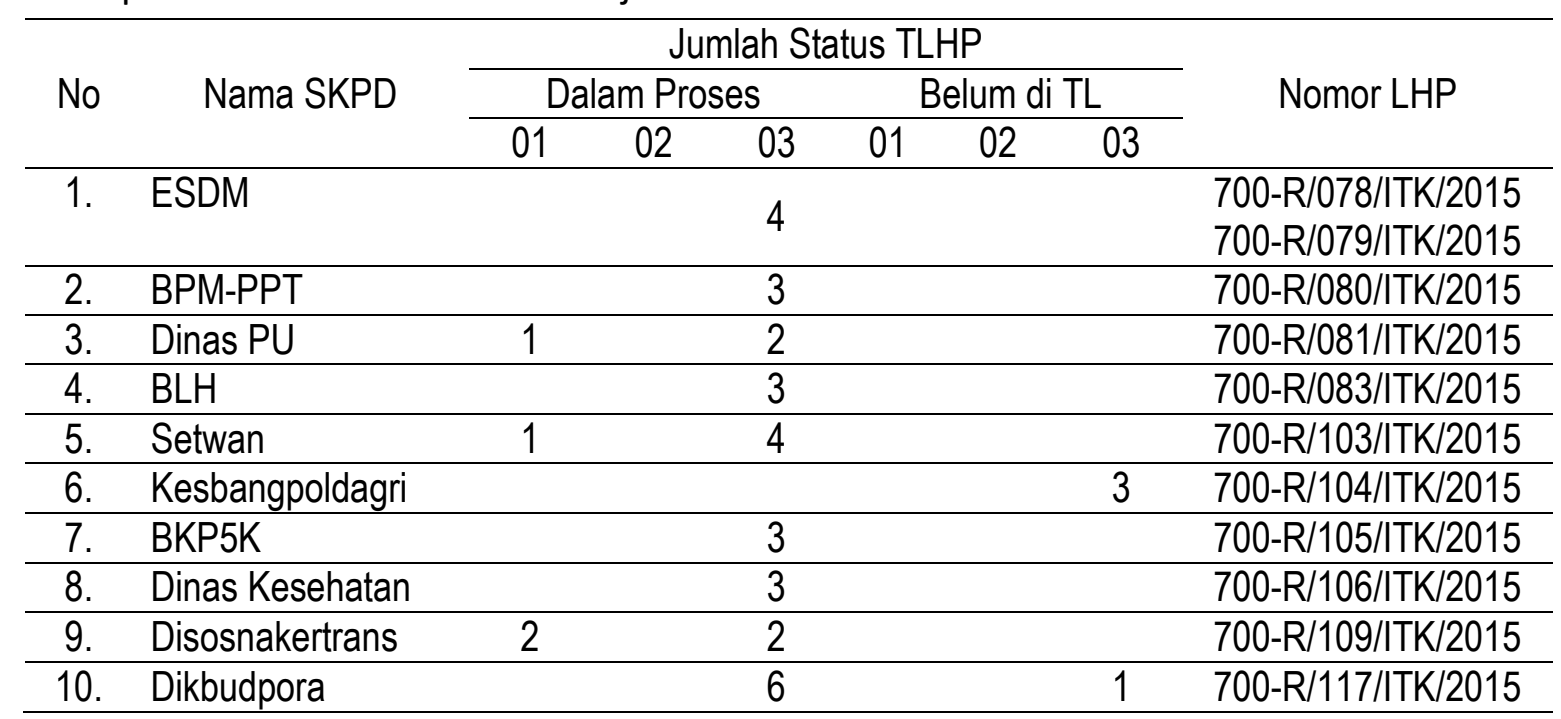

Sumber: LHPT Unit Pemantauan Inspektorat KSB Periode Januari 2016.

Keterangan:

01, 02, 03 = Kode Temuan pada Tabel 1. 


\section{Tema 1: Komunikasi}

Inspektorat Kabupaten Sumbawa Barat sebagai APIP melaksanakan pemeriksaan yang menghasilkan temuan administrasi maupun temuan keuangan yang disusun dalam LHP berdasarkan pada Standar Operasional Prosedur (SOP) untuk menilai kinerja SKPD khususnya dalam bentuk pemeriksaan reguler (Inspektorat KSB, 2015).

LHP digunakan sebagai media komunikasi dalam rangka melakukan pembinaan bagi SKPD. Untuk lebih meyakinkan kepatuhan dalam melaksanakan penyelesaian TLHP oleh SKPD sesuai peraturan Menteri Negara Pendayagunaan Aparatur Negara nomor 9 tahun 2009, dilakukan pemantauan oleh APIP yang dilaksanakan dengan cara melakukan komunikasi lisan (mekanisme rapat atau kunjungan) dan komunikasi tertulis (mekanisme pelaporan/teguran) dengan pejabat yang bertanggungjawab untuk melaksanakan tindak lanjut.

Pemeriksaan auditor Inspektorat Kabupaten Sumbawa Barat secara keseluruhan telah memberikan manfaat bagi kinerja SKPD. Informan menyatakan bahwa evaluasi terhadap kinerja/kegiatan SKPD adalah bentuk manfaat yang dirasakan atas pemeriksaan yang dilakukan guna dapat mengukur sejauh mana kinerja dari SKPD yang telah dilaksanakan sehingga dapat mengetahui kelemahan dari sisi manajemen, sisi keuangan dan sisi lainnya. Hasil tersebut sejalan dengan hasil penelitian yang telah dilakukan oleh (Prihartono, 2009) yang menyatakan bahwa tindak lanjut temuan audit mempunyai andil besar dalam terselenggaranya kepemerintahan yang baik dan bebas dari praktek Korupsi, Kolusi dan Nepotisme.

Penyelesaian TLHP oleh SKPD hanya dapat dilaksanakan dengan baik apabila media komunikasi disajikan secara jelas, lengkap, akurat, objektif dan mudah dipahami. Komunikasi yang telah dibangun auditor dalam bentuk LHP, dapat dirasakan manfaatnya oleh SKPD, apabila pejabat yang bertanggung jawab berkomitmen untuk melaksanakan penyelesaian TLHP auditor Inspektorat Kabupaten Sumbawa Barat sehingga dapat membantu dalam melakukan perbaikan sesuai rekomendasi.

Keberhasilan penyelesaian TLHP tersebut menunjukkan bahwa komunikasi sudah terjalin dengan baik antara pemeriksa dengan yang diperiksa dan antara atasan dengan bawahan pada SKPD atau manajemen. Penyelesaian TLHP oleh SKPD di Kabupaten Sumbawa Barat adalah sebagai wujud kepatuhan dalam mengimplikasikan kebijakan sesuai Peraturan Menteri Negara Pendayagunaan Aparatur Negara nomor 9 tahun 2009 sehingga SKPD di Kabupaten Sumbawa Barat dapat merasakan manfaat dari pemeriksaan yang dilakukan oleh auditor.

\section{Tema 2: Sumber daya}

Tantangan untuk mewujudkan terselenggaranya kepemerintahan yang baik dan bebas dari praktek Korupsi, Kolusi dan Nepotisme, menuntut SKPD di Kabupaten Sumbawa Barat untuk mengalokasikan sumber daya yang dimiliki secara efektif dan efisien dalam melaksanakan program/kegiatan. Komponen sumberdaya meliputi jumlah pegawai, keahlian dari para pegawai, informasi yang relevan dan cukup 
untuk mengimplementasikan kebijakan dan pemenuhan sumber-sumber terkait dalam pelaksanaan program, adanya kewenangan yang menjamin bahwa program dapat mencapai tujuan yamg diharapkan, serta adanya fasilitas-fasilitas pendukung yang dapat dipakai untuk melakukan kegiatan program seperti dana dan sarana prasarana.

Penilaian efektivitas dan efisiensi sumber daya yang digunakan SKPD dapat dilakukan dengan pengawasan internal melalui pemeriksaan oleh auditor Inspektorat. Untuk dapat mencapai hasil pengawasan yang optimal, maka setiap temuan hasil pengawasan APIP wajib ditindaklanjuti oleh SKPD secara konsisten yang menekankan pada tanggung jawab kepala/pimpinan dalam pengembangan pegawai. Kegagalan dalam melaksanakan penyelesaian TLHP oleh SKPD, apapun sebabnya dapat dikatakan sebagai suatu bentuk pemborosan dalam penggunaan sumber daya keuangan daerah dan sumber daya manusia.

Kesulitan akan sumber daya manusia juga sering terjadi di SKPD dikarenakan bahwa sekarang ini sulit sekali seorang pegawai mau untuk diangkat menjadi bendahara sekalipun pegawai tersebut berlatar belakang akuntansi atau ketika seseorang pegawai tersebut sudah mulai paham terhadap pengelolaan keuangan dan akuntansi (Tarigan \& Nurtanzila, 2013). Kesulitan tersebut senada dengan hasil wawancara dalam penelitian ini yang mengakibatkan masalah sumber daya manusia sering menjadi penyebab munculnya temuan dalam pemeriksaan.

Hasil wawancara dengan informan disimpulkan bahwa penyebab munculnya temuan pemeriksaan auditor Inspektorat Kabupaten Sumbawa Barat karena adanya keterbatasan instrumen pendukung dalam penyelenggaraan dinas dan birokrasi yaitu keterbatasan jumlah dan kapasitas SDM dalam hal pengelolaan administrasi dan keuangan. Hasil penelitian tersebut juga sejalan dengan hasil penelitian yang telah dilakukan oleh (Suryanto, 2016) yang meyatakan bahwa penyebab adanya temuan pada saat dilakukan pemeriksaan adalah dari faktor intern yaitu sumberdaya manusia perangkat organisasi yang tidak merata kemampuannya pada jajaran pemerintahan dan sumberdaya manusia pimpinan dalam mengarahkan, memotivasi, membimbing dan mengkoordinasikan kepada bawahan yang belum maksimal.

Sumber daya memiliki peranan penting dalam memberikan kontribusi terhadap pencapaian tujuan SKPD. Sumberdaya manusia yang tidak memadai berakibat tidak dapat dilaksanakannya program secara sempurna sehingga keberhasilan dalam implementasi kebijakan khususnya upaya penyelesaian TLHP akan sulit tercapai. Untuk itu perlu adanya manajemen SDM yang baik dalam rangka penyelesaian TLHP agar tujuan pemeriksaan Inspektorat Kabupaten Sumbawa Barat dapat tercapai.

\section{Tema 3: Sikap birokrasi atau pelaksana}

Tindak lanjut laporan hasil pengawasan menjadi sangat penting karena berhasil atau tidaknya pengawasan penyelenggaraan pemerintah daerah dapat diketahui dari tingkat kepatuhan pemerintah daerah dalam melaksanakan rekomendasi hasil pemeriksaan pejabat pengawasan pemerintah (Hasmawali, 2012). 
Pada tingkat unit kerja, faktor yang mempengaruhi efektivitas implementasi kebijakan penyelesaian TLHP adalah sikap implementor. Kepala/pimpinan sebagai penanggung jawab penyelesaian TLHP yang memiliki kewenangan di SKPD telah menyetujui dan menandatangani isi LHP berupa rekomendasi oleh auditor Inspektorat Kabupaten Sumbawa Barat, sehingga wajib untuk dilaksanakan penyelesaiannya. Wujud dari dukungan pimpinan ini adalah menempatkan kebijakan menjadi prioritas utama, penempatan pelaksana penyelesaian secara baik, dan penyediaan dana yang cukup guna memberikan ruang bagi para pelaksana penyelesaian TLHP.

Hasil penelitian tentang komitmen pimpinan SKPD di Kabupaten Sumbawa Barat, disimpulkan bahwa pimpinan memiliki komitmen dan menjadikan penyelesaian TLHP sebagai prioritas utama sehingga akan dapat melaksanakan penyelesaian TLHP lebih baik dibandingkan dengan pimpinan yang kurang berkomitmen. Bentuk komitmen pimpinan SKPD berupa koordinasi dengan semua pihak yang terkait guna mendiskusikan langkah-langkah ataupun solusi penyelesaian TLHP.

Hasil penelitian tersebut senada dengan hasil penelitian yang dilakukan oleh (Arini, 2014) yang menjelaskan perlunya dukungan dalam hal komitmen, kepemimpinan, motivasi dan pengkomunikasian manajer di semua lini pelaksanaan tindak lanjut LHP SPI dalam bentuk kebijakan tertulis dan semua manajer perlu berkoordinasi dalam upaya pelaksanaan tindak lanjut, serta pentingnya dilakukan evaluasi dan monitoring pelaksanaan tindak lanjut LHP oleh SPI.
Sebagai wujud pelaksanaan penyelesaian TLHP dalam hal pelaporan yang telah dilakukan oleh SKPD, sesuai dengan yang dinyatakan oleh informan pada hasil penelitian ini bahwa dilakukan penyerahan dokumen-dokumen sebagai bukti atas penyelesaian TLHP, baik temuan yang terkait administrasi maupun temuan yang terkait keuangan. Khusus temuan keuangan berupa pengembalian dilampirkan bukti penyetoran yaitu bukti Surat Tanda Setor (STS). Seluruh bukti penyelesaian TLHP tersebut diserahkan ke unit pemantauan Inspektorat Kabupaten Sumbawa Barat dengan disertai tanda terima.

Hasil penelitian terkait dengan bukti penyetoran penyelesaian TLHP senada dengan hasil penelitian oleh (Hasymi, 2016) yang menyatakan bahwa auditi atau unit kerja dalam melakukan pengeluaran uang atau penerimaan uang perlu didukung dokumen yang sah dan tidak lengkap keterangan pada dokumen dalam rangka peningkatan pengelolaan keuangan.

Pelaksanaan penyelesaian TLHP sebelum batas waktu penyelesaian sesuai dengan rekomendasi auditor Inspektorat Kabupaten Sumbawa Barat merupakan kewajiban yang harus dilaksanakan sebagai wujud kepatuhan SKPD dalam Peraturan Menteri Negara Pendayagunaan Aparatur Negara nomor 9 tahun 2009

Dalam upaya penyelesaian TLHP oleh SKPD sebaiknya perlu dijelaskan juga bahwa SKPD telah menindaklanjuti saran/rekomendasi dari auditor Inspektorat dengan cara yang berlainan dengan saran/rekomendasi yang diberikan dalam LHP, maka auditor harus melakukan penilaian terhadap efektivitas penyelesaian 
tindak lanjut yang dilakukan tersebut. Auditor tidak harus memaksakan rekomendasinya ditindaklanjuti namun harus dapat menerima langkah lain yang ternyata lebih efektif (AAIPI, 2013).

Tema 4: Struktur organisasi serta tata aliran kerja birokrasi.

SKPD harus melibatkan semua komponen dalam organisasi dengan membentuk pola hubungan tugas dalam rangka penyelesaian TLHP, terutama terhadap yang terkait langsung dengan rekomendasi. Pola hubungan tugas tersebut dikoordinir oleh kepala/pimpinan SKPD. Turut sertanya tiaptiap level/bagian organisasi dalam penyelesaian TLHP akan membantu dan meningkatkan komunikasi menjadi lebih baik sehingga mendorong adanya koordinasi yang baik. Struktur organisasi memiliki pengaruh yang signifikan terhadap implementasi kebijakan dalam rangka pelaksanaan penyelesaian TLHP.

Para pelaksana sebagai implementor kebijakan mungkin memahami maksud dan tujuan dari rekomendasi auditor dalam LHP, namun seringkali mengalami kegagalan dalam upaya penyelesaiannya, yang diakibatkan karena tata aliran kerja birokrasi masih belum berjalan sebagaimana mestinya. Hasil penelitian yang dijelaskan oleh informan tentang kendala-kendala dalam melaksanakan penyelesaian TLHP menyatakan bahwa kendala yang sering dijumpai adalah terhadap temuan yang terkait dengan keuangan, biasanya akan membutuhkan waktu yang agak lama, apalagi terkait dengan pihak ketiga/rekanan yang tidak jelas alamatnya atau sudah pindah.
Kegagalan SKPD mengatasi kendala dalam penyelesaian TLHP akan dapat mempengaruhi penilaian kinerja SKPD dalam rangka kepatuhan melaksanakan implementasi kebijakan penyelesaian TLHP. SKPD tersebut dapat dikatakan belum sepenuhnya memanfaatkan fungsi pemeriksaan sebagai salah satu bentuk pembinaan yang dilakukan oleh auditor Inspektorat Kabupaten Sumbawa Barat melalui rekomendasi dalam LHP. Temuan dalam hal pemanfaatan hasil pemeriksaan oleh SKPD pada penelitian ini, sejalan dengan penelitian (Hasanah, 2012) yang menyatakan bahwa hasil pemeriksaan yang dilaksanakan oleh Inspektorat belum sepenuhnya dimanfaatkan sebagai feedback (umpan balik) untuk memperbaiki dan meningkatkan kinerja SKPD.

Adapun terkait dengan sanksi tidak dilaksanakannya penyelesaian TLHP Auditor Inspektorat Kabupaten Sumbawa Barat, informan tersebut juga menjelaskan bahwa saksi yang dapat diberikan adalah dalam bentuk sanksi administrasi kepegawaian yang biasanya sesuai dengan Peraturan Pemerintah nomor 53 tahun 2010 tentang Disiplin Pegawai Negeri Sipil. Hal tersebut senada dengan apa yang dijelaskan dalam Peraturan Menteri Negara Pendayagunaan Aparatur Negara nomor 9 tahun 2009 yang menjelaskan bahwa pimpinan unit kerja pada instansi pemerintah yang tidak melaksanakan kewajiban menindaklanjuti rekomendasi dalam LHP dikenakan sanksi sesuai dengan ketentuan peraturan perundang-undangan yang berlaku yaitu undang-undang nomor 15 tahun 2004 tentang Perbendaharaan Negara pasal 20 ayat 5 yang menyatakan bahwa pejabat yang 
diketahui tidak melaksanakan kewajiban sebagaimana dimaksud pada ayat (1) yaitu pejabat wajib menindaklanjuti rekomendasi dalam laporan hasil pemeriksaan, dapat dikenai sanksi administratif sesuai dengan ketentuan peraturan perundang-undangan di bidang kepegawaian, yaitu: Peraturan Pemerintah Nomor 30 tahun 1980 tentang Peraturan Disiplin Pegawai Negeri Sipil yang sudah diubah menjadi Peraturan Pemerintah nomor 53 tahun 2010 tentang Disiplin Pegawai Negeri.

\section{SIMPULAN}

Kendala utama penyebab masih adanya temuan yang tidak dan atau belum selesai ditindaklanjuti adalah kurangnya komunikasi yang baik di tingkatan Manajemen SKPD pada Kabupaten Sumbawa Barat dan masih kurangnya Sumber Daya Manusia (SDM) yang kompeten, sehingga penyelesaian TLHP oleh SKPD yang merupakan di bawah pengawasan Inspektorat Kabupaten Sumbawa Barat yang sesuai amanat Peraturan Menteri Negara Pendayagunaan Aparatur Negara nomor 9 tahun 2009 belum tercapai secara maksimal dengan masih adanya TLHP yang belum dan atau tidak ditindaklanjuti.

Untuk ke depannya agar para kepala/pimpinan SKPD yang secara umum memiliki komitmen dalam upaya penyelesaian dapat mengkomunikasikan lebih baik dan SKPD harus melibatkan semua komponen dalam organisasi dengan membentuk pola hubungan tugas dalam rangka penyelesaian TLHP. Dalam pelaksanaan Implementasi kebijakan merupakan tahapan yang sangat penting dalam proses kebijakan publik. Dalam konteks pengawasan, terlaksananya penyelesaian diwujudkan melalui kepatuhan dalam melaksanakan penyelesaian TLHP sehingga menjadi penentu keberhasilan dalam pengawasan pemerintah daerah oleh APIP.

\section{DAFTAR PUSTAKA}

AAIPI. (2013). Standar Audit Intern Pemerintah Indonesia. Jakarta, Indonesia: Asosiasi Auditor Internal Pemerintah Indonesia.

Akib, H. (2010). Implementasi Kebijakan: Apa, Mengapa, dan Bagaimana. Jurnal Administrasi Publik, 1(1), 6.

Arini, I. G. (2014). Analisis peran manajer dalam tindak lanjut laporan hasil pemeriksaan oleh satuan kerja pemeriksaan intern di RSUP Sanglah Denpasar tahun 2012. Depok: Universitas Indonesia.

Dewi, K. M., \& Pamudji, S. (2013). Analisis faktor-faktor yang mempengaruhi ketepatwaktuan dan audit delay penyampaian laporan keuangan. Diponogoro Journal of Accounting, 2(2), 1-13.

Hasanah, N. S. (2012). Studi fenomenologis terhadap kualitas audit aparat Inspektorat daerah (Studi pada Inspektorat Provinsi NTB). Mataram: Universitas Mataram.

Hasmawali, A. (2012, Juni 7). Analisis hukum terhadap tindak lanjut Laporan Hasil Pengawasan. Dipetik Agustus 16, 2016, dari Website Resmi Inspektorat Provinsi Sulawesi Selatan: http://inspektoratsulsel.id/

Hasymi, M. (2016, Februari). Evaluasi tindak lanjut temuan audit internal sebagai unsur mengoptimalkan pengelolaan keuangan. Kalbisocio Jurnal Bisnis dan Komunikasi, 3(1), 67-78. 
Inspektorat KSB. (2015). Kebijakan pengawasan Inspektorat Kabupaten Sumbawa Barat. Taliwang, Nusa Tenggara Barat, Indonesia: Tim Penyusun Kebijakan Inspektorat KSB.

Inspektorat KSB. (2015). Rencana Strategis Satuan Kerja Perangkat Daerah (SKPD). Taliwang, NTB, Indonesia: Tim Penyusun Renstra Inspektorat Kabupaten Sumbawa Barat.

Prihartono, E. (2009). Pelaksanaan pengawasan fungsional dalam rangka menuju optimalisasi kinerja. e-journal UNDIP, 5, 1-18.

Sofyani, H. (2015, Desember). Hubungan karakteristik pegawai pemerintah daerah dan implementasi sistem pengukuran kinerja:perspektif imorfisma institusional. JAAl, 19(2), 153-173.

Suryanto, A. (2016). Studi keterlambatan tindak lanjut temuan hasil pemeriksaan Inspektorat daerah Kabupaten Kulonprogo D.I Yogyakarta dan implementasi manajerial. Interdisciplinary Postgraduate Student Conference 1st (hal. 83-90). Yogyakarta: Program Pascasarjana Universitas Muhammadiyah Yogyakarta (PPs UMY).

Tarigan, E. P., \& Nurtanzila, L. (2013, Mei). Standar akuntansi pemerintah dalam mewujudkan akuntabilitas dan transparansi Pengelolaan keuangan daerah. (1, Penyunt.) Jurnal Administrasi Kebijakan Publik, 17, 40.

Peraturan Menteri Dalam Negeri nomor 23 tahun 2007 tentang Pedoman Tata Cara Pengawasan atas Penyelenggaraan Pemerintah Daerah.

Peraturan Menteri Dalam Negeri nomor 64 tahun 2007 tentang Pedoman Teknis Organisasi dan Tata Kerja Inspektorat Provinsi dan Kabupaten/Kota.

Peraturan Menteri Pendayagunaan Aparatur Negara nomor 9 tahun 2009 tentang Pedoman Umum Pelaksanaan Pemantauan, Evaluasi, dan Pelaporan Tindak Lanjut Hasil Pengawasan Fungsional.

Peraturan Pemerintah nomor 30 tahun 1980 tentang Peraturan Disiplin Pegawai Negeri Sipil.

Peraturan Pemerintah nomor 53 tahun 2010 tentang Disiplin Pegawai Negeri.

Peraturan Pemerintah Republik Indonesia nomor 60 tahun 2008 tentang Sistem Pengendalian Intern Pemerintah.

Peraturan Pemerintah Republik Indonesia nomor 79 tahun 2005 tentang Pedoman Pembinaan dan Pengawasan Penyelenggaraan Pemerintahan Daerah.

Undang-Undang nomor 15 tahun 2004 tentang Perbendaharaan Negara 


\section{LAMPIRAN}

Model Peraga Penyelesaian TLHP oleh SKPD berdasarkan tema-tema yang ditetapkan

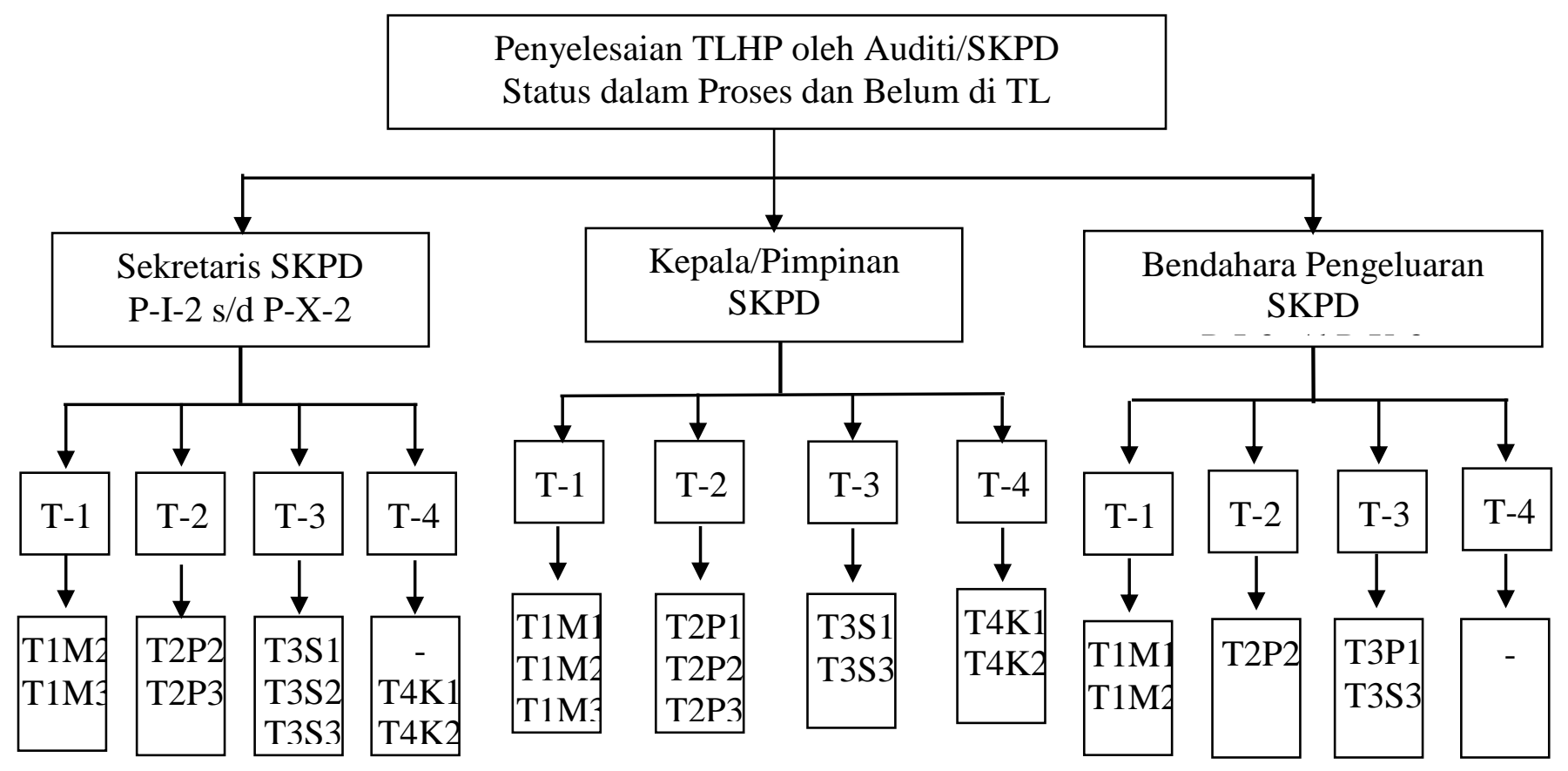

\section{Keterangan:}

P-I-1 s/d P-X-1 = Informan sebagai Kepala/Pimpinan SKPD

P-I-2 s/d P-X-2 = Informan sebagai Sekretaris SKPD

P-I-3 s/d P-X-3 = Informan sebagai Bendahara Pengeluaran SKPD

T-1 = Tema 1: Komunikasi

T-2 = Tema 2: Sumber daya

T-3 = Tema 3: Sikap birokrasi atau pelaksana

T-4 = Tema 4: Struktur organisasi serta tata aliran birokrasi

T1M1 = Evaluasi terhadap SPI

T1M2 = Evaluasi terhadap program/kegiatan

T1M3 = Membantu manajemen

$\mathrm{T} 2 \mathrm{P} 1=$ Keterbatasan sarana dan prasarana

$\mathrm{T} 2 \mathrm{P} 2=$ Keterbatasan SDM

T2P3 = Kelemahan atasan langsung (pengawasan melekat)

T3S1 = Komitmen pimpinan/atasan

T3S2 = Pembinaan SDM

T3S3 = Pelaporan TL (bukti penyelesaian TLHP)

T4K1 = Penagihan kerugian daerah

T4K2 $=$ Sanksi/hukuman

= Tidak menunjukkan adanya indikator 
MATRIK ANALISIS TEMATIK DATA KUALITATIF

\begin{tabular}{|c|c|c|c|c|c|c|c|c|c|c|c|c|c|}
\hline \multirow{2}{*}{\multicolumn{2}{|c|}{\begin{tabular}{|c|} 
Kode \\
Informan
\end{tabular}}} & \multirow{3}{*}{$\begin{array}{l}\text { Kode Pedoman Wawancara } \\
3 a b, 3 c, 3 d e f j k, 3 g\end{array}$} & \multicolumn{3}{|c|}{ T1 } & \multicolumn{3}{|c|}{$\mathbf{T} 2$} & \multicolumn{3}{|c|}{ T3 } & \multicolumn{2}{|c|}{ T4 } \\
\hline & & & \multirow[t]{2}{*}{ M1 } & \multirow{2}{*}{$\frac{\text { M2 }}{\sqrt{ }}$} & \multirow[t]{2}{*}{ M3 } & \multirow[t]{2}{*}{ P1 } & \multirow{2}{*}{$\frac{\mathbf{P 2}}{\sqrt{ }}$} & \multirow[t]{2}{*}{ P3 } & \multirow{2}{*}{$\frac{\text { S1 }}{\sqrt{ }}$} & \multirow[t]{2}{*}{ S2 } & \multirow{2}{*}{$\frac{\text { S3 }}{\sqrt{ }}$} & \multirow{2}{*}{$\frac{\mathrm{K} 1}{\sqrt{ }}$} & \multirow[t]{2}{*}{$\mathbf{K} 2$} \\
\hline P-I- & 1 & & & & & & & & & & & & \\
\hline & 2 & 4ab, 4c, 4defghij, 4k & & & $\sqrt{ }$ & & $\sqrt{ }$ & & $\sqrt{ }$ & $\sqrt{ }$ & $\sqrt{ }$ & $\sqrt{ }$ & \\
\hline & 3 & $5 \mathrm{ab}, 5 \mathrm{c}, 5 \mathrm{defgh}, 5 \mathrm{i}$ & & $\sqrt{ }$ & & $\sqrt{ }$ & & & $\sqrt{ }$ & & $\sqrt{ }$ & - & - \\
\hline \multirow[t]{3}{*}{ P-II- } & 1 & $3 a b, 3 c, 3 d e f j k, 3 g$ & & & & & & & & & & & \\
\hline & 2 & 4ab, 4c, 4defghij, 4k & $\sqrt{ }$ & $\sqrt{ }$ & $\sqrt{ }$ & & $\sqrt{ }$ & $\sqrt{ }$ & $\sqrt{ }$ & $\sqrt{ }$ & $\sqrt{ }$ & - & - \\
\hline & 3 & $5 \mathrm{ab}, 5 \mathrm{c}, 5 \mathrm{defgh}, 5 \mathrm{i}$ & & $\sqrt{ }$ & & & $\sqrt{ }$ & & $\sqrt{ }$ & & $\sqrt{ }$ & - & - \\
\hline \multirow[t]{3}{*}{ P-III- } & 1 & 3ab, 3c, 3defjk, 3g & & & & & & & & & & & \\
\hline & 2 & 4ab, 4c, 4defghij, 4k & & $\sqrt{ }$ & & & $\sqrt{ }$ & & $\sqrt{ }$ & $\sqrt{ }$ & $\sqrt{ }$ & - & - \\
\hline & 3 & $5 \mathrm{ab}, 5 \mathrm{c}, 5 \mathrm{defgh}, 5 \mathrm{i}$ & - & - & - & $\sqrt{ }$ & & & $\sqrt{ }$ & & $\sqrt{ }$ & - & - \\
\hline \multirow[t]{3}{*}{ P-IV- } & 1 & $3 a b, 3 c, 3 d e f j k, 3 g$ & & $\sqrt{ }$ & $\sqrt{ }$ & & $\sqrt{ }$ & & $\sqrt{ }$ & $\sqrt{ }$ & & - & - \\
\hline & 2 & 4ab, 4c, 4defghij, 4k & - & - & - & $\sqrt{ }$ & & & $\sqrt{ }$ & $\sqrt{ }$ & $\sqrt{ }$ & & $\sqrt{ }$ \\
\hline & 3 & $5 \mathrm{ab}, 5 \mathrm{c}, 5 \mathrm{defgh}, 5 \mathrm{i}$ & & $\sqrt{ }$ & $\sqrt{ }$ & - & - & - & $\sqrt{ }$ & & $\sqrt{ }$ & - & - \\
\hline \multirow[t]{3}{*}{ P-V- } & 1 & $3 \mathrm{ab}, 3 \mathrm{c}, 3$ defjk, 3g & - & - & - & & $\sqrt{ }$ & & $\sqrt{ }$ & & $\sqrt{ }$ & $\sqrt{ }$ & \\
\hline & 2 & 4ab, 4c, 4defghij, 4k & & $\sqrt{ }$ & & & $\sqrt{ }$ & & $\sqrt{ }$ & & & - & - \\
\hline & 3 & $5 \mathrm{ab}, 5 \mathrm{c}, 5 \mathrm{defgh}, 5 \mathrm{i}$ & - & - & - & & $\sqrt{ }$ & & $\sqrt{ }$ & & $\sqrt{ }$ & - & - \\
\hline \multirow[t]{3}{*}{ P-VI- } & 1 & 3ab, 3c, 3defjk, 3g & & & $\sqrt{ }$ & & $\sqrt{ }$ & $\sqrt{ }$ & $\sqrt{ }$ & $\sqrt{ }$ & $\sqrt{ }$ & & $\sqrt{ }$ \\
\hline & 2 & 4ab, 4c, 4defghij, 4k & & & $\sqrt{ }$ & & $\sqrt{ }$ & & $\sqrt{ }$ & $\sqrt{ }$ & $\sqrt{ }$ & & $\sqrt{ }$ \\
\hline & 3 & $5 \mathrm{ab}, 5 \mathrm{c}, 5 \mathrm{defgh}, 5 \mathrm{i}$ & & $\sqrt{ }$ & & $\sqrt{ }$ & & & $\sqrt{ }$ & & $\sqrt{ }$ & - & - \\
\hline \multirow[t]{3}{*}{ P-VII- } & 1 & 3ab, 3c, 3defjk, 3g & & $\sqrt{ }$ & & & & $\sqrt{ }$ & $\sqrt{ }$ & $\sqrt{ }$ & $\sqrt{ }$ & $\sqrt{ }$ & \\
\hline & 2 & 4ab, 4c, 4defghij, 4k & & & $\sqrt{ }$ & & $\sqrt{ }$ & & $\sqrt{ }$ & & $\sqrt{ }$ & $\sqrt{ }$ & \\
\hline & 3 & $5 \mathrm{ab}, 5 \mathrm{c}, 5 \mathrm{defgh}, 5 \mathrm{i}$ & & $\sqrt{ }$ & & & $\sqrt{ }$ & & $\sqrt{ }$ & & $\sqrt{ }$ & - & - \\
\hline \multirow[t]{2}{*}{ P-VIII- } & 1 & 3ab, 3c, 3defjk, 3g & & & $\sqrt{ }$ & & $\sqrt{ }$ & & $\sqrt{ }$ & $\sqrt{ }$ & $\sqrt{ }$ & $\sqrt{ }$ & \\
\hline & 2 & 4ab, 4c, 4defghij, 4k & - & - & - & $\sqrt{ }$ & & & $\sqrt{ }$ & $\sqrt{ }$ & $\sqrt{ }$ & - & - \\
\hline
\end{tabular}


Jurnal Economia, Volume 13, Nomor 1, April 2017

\begin{tabular}{|c|c|c|c|c|c|c|c|c|c|c|c|c|c|}
\hline \multirow{2}{*}{\multicolumn{2}{|c|}{$\begin{array}{c}\text { Kode } \\
\text { Informan }\end{array}$}} & \multirow{3}{*}{$\begin{array}{l}\text { Kode Pedoman Wawancara } \\
\text { 5ab, 5c, 5defgh, 5i }\end{array}$} & \multicolumn{3}{|c|}{ T1 } & \multicolumn{3}{|c|}{ T2 } & \multicolumn{3}{|c|}{ T3 } & \multicolumn{2}{|c|}{ T4 } \\
\hline & & & \multirow[t]{2}{*}{ M1 } & \multirow{2}{*}{$\frac{\text { M2 }}{\sqrt{ }}$} & \multirow[t]{2}{*}{ M3 } & \multirow{2}{*}{$\frac{\mathbf{P 1}}{\sqrt{ }}$} & \multirow{2}{*}{$\frac{\mathbf{P 2}}{\sqrt{ }}$} & \multirow[t]{2}{*}{ P3 } & \multirow{2}{*}{$\frac{\mathbf{S 1}}{\sqrt{ }}$} & \multirow[t]{2}{*}{$\mathbf{S 2}$} & \multirow{2}{*}{$\frac{\text { S3 }}{\sqrt{ }}$} & \multirow{2}{*}{$\frac{\mathbf{K 1}}{-}$} & \multirow{2}{*}{$\frac{\mathrm{K} 2}{-}$} \\
\hline & 3 & & & & & & & & & & & & \\
\hline \multirow[t]{3}{*}{ P-IX- } & 1 & 3ab, 3c, 3defjk, 3g & & & $\sqrt{ }$ & $\sqrt{ }$ & $\sqrt{ }$ & & $\sqrt{ }$ & $\sqrt{ }$ & $\sqrt{ }$ & $\sqrt{ }$ & \\
\hline & 2 & 4ab, 4c, 4defghij, 4k & & & $\sqrt{ }$ & - & - & - & & $\sqrt{ }$ & $\sqrt{ }$ & - & - \\
\hline & 3 & $5 \mathrm{ab}, 5 \mathrm{c}, 5 \mathrm{defgh}, 5 \mathrm{i}$ & & $\sqrt{ }$ & & & $\sqrt{ }$ & & $\sqrt{ }$ & & $\sqrt{ }$ & - & - \\
\hline $\mathrm{P}-\mathrm{X}-$ & 1 & 3ab, 3c, 3defjk, 3gi & $\sqrt{ }$ & & $\sqrt{ }$ & $\sqrt{ }$ & $\sqrt{ }$ & & $\sqrt{ }$ & $\sqrt{ }$ & $\sqrt{ }$ & $\sqrt{ }$ & \\
\hline
\end{tabular}

\section{Keterangan:}

Informan P-I-1 s/d P-X-1 sebagai Kepala/pimpinan SKPD

$3 \mathrm{ab}=$ Pedoman wawancara yang diajukan kepada informan sesuai dengan tema 1

3c = Pedoman wawancara yang diajukan kepada informan sesuai dengan tema 2

3defjk = Pedoman wawancara yang diajukan kepada informan sesuai dengan tema 3

$3 \mathrm{~g}=$ Pedoman wawancara yang diajukan kepada informan sesuai dengan tema 4

Informan P-I-2 s/d P-X-2 sebagai Sekretaris SKPD

$4 \mathrm{ab}=$ Pedoman wawancara yang diajukan kepada informan sesuai dengan tema 1

$4 \mathrm{c}=$ Pedoman wawancara yang diajukan kepada informan sesuai dengan tema 2

4defghij= Pedoman wawancara yang diajukan kepada informan sesuai dengan tema 3

$4 \mathrm{k}=$ Pedoman wawancara yang diajukan kepada informan sesuai dengan tema 4

Informan P-I-3 s/d P-X-3 sebagai Bendahara Pengeluaran SKPD

$5 \mathrm{ab}=$ Pedoman wawancara yang diajukan kepada informan sesuai dengan tema 1

$5 \mathrm{c}=$ Pedoman wawancara yang diajukan kepada informan sesuai dengan tema 2

5 defgh $=$ Pedoman wawancara yang diajukan kepada informan sesuai dengan tema 3

5i = Pedoman wawancara yang diajukan kepada informan sesuai dengan tema 4 